\title{
Can nigella sativa and pure honey improved chemoradiotherapy effects in advanced pancreatic
} cancer

\begin{abstract}
The cancer treatments cause many side effects in patients. This is more important in pancreatic cancer $(\mathrm{PCa})$ than other types of cancer because the PCa patients already suffer from abdominal pain, nausea, and loss of appetite. Therefore, it is necessary to focus on new treatment ways that decrease the toxicity and increase the survival time in PCa patients. A retrospective study was performed with 20 PCa patients who had nonmetastatic locally advanced inoperable PCa. Patients were divided into 2 groups. Group $1(n=9)$ included patients who received chemoradiotherapy and, taken Nigella sativa(NS) and pure honey $(\mathrm{H})(\mathrm{NS}+\mathrm{H}+\mathrm{CRT}$ group). Group $2(\mathrm{n}=11)$ consisted of patients who treated with concurrent chemoradiotherapy (CRT or control group). The median survival time was 15 months, and $\% 11.11$ of patients $(n=1)$ had a survival time of 36 months in group 1 . In control group (Group 2), the median survival time was 10months. Results revealed that chemoradiotherapy supported by NS and pure honey consumption increased the survival time when used before and during treatment of PCa patients.
\end{abstract}

Keywords: gemcitabine, nigella sativa, pure honey, advanced pancreatic cancer
Volume 7 Issue 3 - 2017

\author{
Huriye Senay Kiziltan,' Mehmet Kursat \\ Turkdogan, ${ }^{2}$ Ayse Gunes-Bayir, ${ }^{3}$ Ali Hikmet \\ Eris,' Medina Ismaylova, ${ }^{4}$ Ahmed Nadeem \\ Abbasi, ${ }^{5}$ Alpaslan Mayadagli,' Nazmiye \\ Ozsutcu $^{6}$ \\ 'Department of Radiation Oncology, Bezmialem Vakif University, \\ Turkey \\ ${ }^{2}$ Department of internal medicine Dvz of Gastroenterology, \\ Sabahattin Zaim University, Turkey \\ ${ }^{3}$ Department of Nutrition and Dietetics, Bezmialem Vakif \\ University, Turkey \\ ${ }^{4}$ Department of Internal Medicine, Bezmialem Vakif University, \\ Turkey \\ ${ }^{5}$ Department of Oncology, Section of Radiation Oncology, Aga \\ Khan University, Pakistan \\ ${ }^{6}$ Department of General Surgery, Bezmialem Vakif University, \\ Turkey
}

Correspondence: Alpaslan Mayadagli, Faculty of Medical, Department of Radiation Oncology, Bezmialem Vakif University, 34093, Fatih Istanbul,Turkey, Email alpdag@hotmail.com

Received: October 14, 2017 | Published: December 04, 2017
Abbreviations: NS, nigella sativa; IMRT, intensity-modulated radiation therapy; SBRT, stereotactic body radiation therapy; TQ, thymoquinone; DIM, dithymoquinone; COX-2, cyclo-oxygenase-2; $\mathrm{H}$, honey; MLC, multi leaf collimator; CTV, clinical tumor volume; PTV, planning tumor volume; OS, overall survival; MRI, magnetic resonance imaging

\section{Introduction}

Cancer is the formation of different cells the ability to overgrow. Sometimes its formation becomes easier with some factors. The carcinogens, which is one of the causing factors of cancer, and mutations of some genes that supress cancer formation are known the most important contributing factors for cancer. ${ }^{1,2}$ The risk of cancer can be diminished an average of $30-40 \%$ with an adequate diet and exercise. Approximately 5million people in the world would be protected by appropriate diet from cancer each year. ${ }^{3-7}$

Cancer may develop very easily in the pancreas gland due to insulin or Circulating Insulin-Like Growth Factor Binding Proteins related over-enlargement, degeneration. For this reason, the most negatively affected type of cancer from the diet is $\mathrm{PCa} .^{3,5-7}$

PCa incidences were $2.3 \%$ in all cancer of the World According to the National Cancer Information Center of Korea. For gender, 53,070 estimated cases and 41,780 (\%7) expected death for PCa in U.S.A. Generally, PCa incidences are $3 \%$ in all cancer of the World. ${ }^{8}$

More than $80 \%$ of PCa are diagnosed in advanced stages because of fast spread and non-clear early symptoms such as abdominal pain, nausea, and loss of appetite. ${ }^{9}$ Smoking, high-fat diet, chronic pancreatitis, primary sclerosing cholangitis, hereditary pancreatitis, family history of pancreatic cancer and diabetes mellitus are the most common cause of $\mathrm{PCa} .{ }^{10}$

Median survival was 6 to 10 months for advanced PCa. ${ }^{11,12}$ Treatment options for these patients are CT, RT, CRT, and/or palliative surgery. The median survival of advanced $\mathrm{PCa}$ increases to 10 months using concurrent CRT, compared to RT alone. ${ }^{13,14} 5$-fluorouracil (5-FU) and gemcitabine are most using $\mathrm{CT}$ agents in $\mathrm{PCa}$ treatment regimes. ${ }^{15,16}$ Gemcitabine has been the most prominent CT for advanced PCa. ${ }^{12,17}$ However, the survival benefit of gemcitabine is very low and the median survival time was 5.7 months for gemcitabine and 4.4 months for 5 -FU treatment respectively. Therefore more effective therapy is urgently needed in advanced PCa. Many studies have been made to improve the overall survival of patients with using gemcitabine and other agents. ${ }^{18}$ Gemcitabine alone or gemcitabine combination therapies were made which contain capecitabine, 5- FU, irinotecan, pemetrexed 
and oxaliplatin. The response rates were increased by these treatments but significant survival advantage was not shown for the gemcitabine combination therapies over the gemcitabine monotherapy because gemcitabine resistance and increased toxicity. ${ }^{19,20}$ Therefore, a new approach is warranted. It is very important to make a balance between efficacy and quality of life in treatments of $\mathrm{PCa}$, because $\mathrm{PCa}$ patients already suffer from cancer-related symptoms that loss of appetite, fatigue, nausea, vomiting and abdominal pain.

Intensity-modulated radiation therapy (IMRT), stereotactic body radiation therapy (SBRT) or tomotherapy methods most be using as RT, because pancreatic location and possible side effects that diarea, vomiting, hepatic, renal functional anomalities because of surrounded organs in PCa. ${ }^{12,21,22}$ However, treatment outcomes not enough to change in locally advanced pancreatic cancer even these treatments.

Thymoquinone (TQ) shown to some health benefit effects in studies. ${ }^{23-25}$ TQwhich often referred to as black cumin seeds is extracted from the seed of NS. These seeds had been used since a long time for toxicity or primary treatment of diseases. The antioxidant, antiproliferative, cytotoxic, organ safing, antimicrobial effects of 2 to $5 \mathrm{~g}$ of $N S$ demonstrated in multiple studies ${ }^{23-26}$ Cancer Research group reported that the purified extract TQand dithymoquinone (DIM) both were effective in killing the multiple cancer cell lines. TQ and DIM also reduces multi-drug resistance to doxorubicin and etoposide. ${ }^{27}$

TQ alone inhibited cancer cell viability up to $70 \%$ because inhibites anti-apoptotic $\mathrm{Bcl}-2$ and $\mathrm{Bcl}-\mathrm{xL} \mathrm{Mcl}-\mathrm{a}$, survivin, XIAPcyclo-oxygenase-2 (COX-2), PGE-2 accumulation, nuclear factor-kappaB (NF-kappa B) and induces pro-apoptotic molecule Bax in a dose dependent manner. NF-kappa B also may be causes resistance to gemcitabine. The COX-2 enzyme increased metastases that inhibites to apoptosis, also potantiates cell growth, angiogenesis and overe xpressed in PCa. The PCa cells were may sensitized to CT agents by using TQ. A $15-50 \%$ reduction of PCa cells were showed by treatment with TQ or other CT agents. The tumor reduction was obtained $66 \%$ and $58 \%$ by using gemcitabine or oxaliplatin while increase with combination to TQ which $85 \%$ for gemcitabine and $76 \%$ for oxaliplatine respectively. ${ }^{28}$

However combining pre-treatment TQand $\mathrm{CT}$ resulted in a 65 $85 \%$ loss of viable cancer cells through increased apoptosis in $\mathrm{PCa}$ $(\mathrm{P}<0.001)$. CT can decrease viable cancer cells while increases $N F$ kappa $B$ which cause progression and chemoresistance. ${ }^{29}$ TQ can decreases to NF-kappa $B$ and improves treatment results. ${ }^{30}$

Honey has been used as a food source, and current research shown that it may be a beneficial aid to cancer therapy. The antioxidant, immunmodulative and anti-inflammatory action of honey and related to its phenolic constituents was showed in many studies. ${ }^{31-36}$ Ellagic acid, gallic acid, caffeic acid, chlorogenic acid, kaempferol, catechin, quercetin, luteolin, are some fenolic compaunds of honey. ${ }^{36}$ Biswa Mohan and colleagues made a preliminary study about pure honey for decreasing oral mucosal toxicity. The studies shown that topical pure honey reduces oral mucositis as dramatical. ${ }^{37,38}$ The antioxidant, antiproliferative, antimicrobial effects of 3 to $20 \mathrm{~g}$ of honey demonstrated in multiple studies. ${ }^{38-43}$ In Islamic medicine and Iran, the combination of NS with honey is used for alleviating gastrointestinal symptoms like abdominal pain, bloating and diarrhea. ${ }^{44-46} \mathrm{We}$ obtained a study increasing CRT effectiveness with NS and Honey $(\mathrm{H})$ for decreasing oral and gastrointestinal toxicity.

\section{Methods}

A retro-spective study was performed on 20 patients with $\mathrm{PCa}$ who had advanced PCa and came to our clinic between 2012-2014. Their ages ranged from 39 to 70 and Eastern Cooperative Oncology Group (ECOG) performances ranged from 1-4 (Table 1) (Table 2). Patients were divided into 2 groups. 9 patients in the 1 st group who were applied NS, H, RT and concurrent RT and CT (NS+H+CRT group) diagnosed as inoperable advanced PCa. CT and concurrent RT were applicated to 11 patients in the 2nd group (CRT group) who diagnosed as inoperable advanced $\mathrm{PCa}$.

A. NS dust was given $3 \mathrm{gr}$ with 12 hours interval for 7 days and daily $5 \mathrm{~g} \mathrm{H}$ using concurrent with NS orally. After this interval, $\mathrm{CRT}$ and concurrent NS dust and $\mathrm{H}$ was given with same doses and 12 hours interval were used troughout the RT. Gemcitabine used intravenous only $600 \mathrm{mg} / \mathrm{m}^{2}$ weekly in NS+H+CRT group troughout the RT. RT was performed in 28 fractions with $180 \mathrm{cGy}$ fraction and a total of $5040 \mathrm{cGy}$.

B. $600 \mathrm{mg} / \mathrm{m}^{2}$ of intravenous gemcitabine given per week and simultaneous RT was performed in 28 fractions with $180 \mathrm{cGy}$ fraction and 5040cGy total dose in the 2nd group (CRT group). Staging was determined according to the American Joint Committee of Cancer $7^{\text {th }}$ edition with FDG-positron emitting tomography scans to evaluate distant metastasis. ${ }^{20}$ Eastern Cooperative Oncology Group (ECOG) performance status, pre and post-treatment contrast enhanced Computed Tomography (CT)

imaging and CA19-9 (Carbohydrate Antigen 19-9) levels were performed for response evaluation.

Table I Pre-treatment patient characteristics of group I (NS+H+CRT)

\begin{tabular}{lll}
\hline Characters & Number & $\%$ \\
\hline Gender & 5 & 55.55 \\
Male & 4 & 44.44 \\
Female & & \\
Age & 2 & 22.22 \\
$35-49$ & 4 & 44.44 \\
$50-59$ & 3 & 33.33 \\
$60-70$ & & \\
CA19-9 & 3 & 33.33 \\
$400-1000$ & 6 & 66.66 \\
1000-4000 & & \\
Tumor Location & 7 & 77.77 \\
Head of P & 2 & 22.22 \\
Tail of P & & \\
ECOG Scoring & 0 & 0 \\
0-I & 5 & 55.55 \\
2 & 4 & 44.44 \\
3 & 9 & 100 \\
Toplam & & \\
\hline
\end{tabular}

NS, nigella sativa; $\mathrm{H}$, pure honey; CRT, chemoradiotherapy; P, pancreas 
Table 2 Pre-treatment patient characteristics of group 2 (CRT)

\begin{tabular}{|c|c|c|}
\hline Patient characters & Number & $\%$ \\
\hline \multicolumn{3}{|l|}{ Gender } \\
\hline Male & 6 & 54.54 \\
\hline Female & 5 & 45.45 \\
\hline \multicolumn{3}{|l|}{ Age } \\
\hline $35-49$ & 3 & 27.27 \\
\hline $50-59$ & 5 & 45.45 \\
\hline $60-70$ & 3 & 27.27 \\
\hline \multicolumn{3}{|l|}{ CA19-9 } \\
\hline $400-1000$ & 8 & 72.72 \\
\hline $1000-4000$ & 3 & 27.27 \\
\hline \multicolumn{3}{|l|}{ Tumor location } \\
\hline Head & 8 & 72.72 \\
\hline Tail & 3 & 27.27 \\
\hline \multicolumn{3}{|l|}{ ECOG scoring } \\
\hline $0-1$ & 2 & 18.18 \\
\hline 2 & 6 & 54.54 \\
\hline 3 & 3 & 25 \\
\hline Toplam & 12 & 100 \\
\hline
\end{tabular}

\section{Radiotherapy}

RT was performed in group 1 and 2 with a Varian Linear Accelerator (MNT, Health Care and Trade Corporation, Turkey, Bozlu Holding) device. In the 1st and 2nd group, the pancreatic tumors were treated with Three Dimensional (3-D) conformal or dynamic IMRT (Intensive Modulated Radiation Therapy) method with MLC (Multi Leaf Collimator) blocked fields, with 6 and $18 \mathrm{MeV}$ X-rays, including Gross Tumor Volume (GTV), pancreatic and regional lymphatics that Clinical Target Volume(CTV) and Planning Tumour Volume (PTV). Total dose of $5040 \mathrm{cGy}$ was applied to 28 fractions with $180 \mathrm{cGy} 5$ times per week.

Clinical tumor volume (CTV) was created by giving margin to GTV and lymphatic zone only $0.5 \mathrm{~mm}$ to avoid toxicity. The planning tumor volume (PTV) was established by giving a $1-\mathrm{mm}$ margin to CTV. $85-95 \%$ of the targeted radiation dose received $95 \%$ of the tumor in the radiation field (Figure 1). Conformity index and homogeneity index were median 0.97 and 0.35 respectivelly for PTV (Table 3).

\section{Statistical analyses}

Statistical Analyses were performed with Mann Witney U test. The differences of between the two groups $\mathrm{p} \leq 0.05$ values accepted as significant according to Mann Witney U test. Kaplan Meier method was used for obtained survival curve and calculated survival rates in two groups of PCa patients.

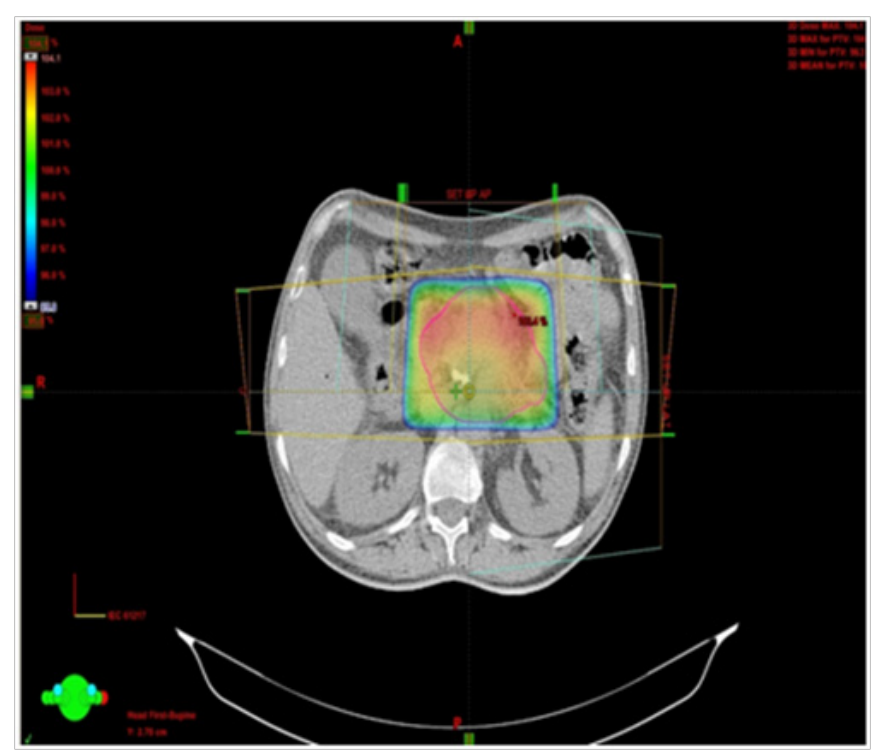

Figure I Isodose distribution of radiation planning on PCa patients.

Table 3 Radiotherapy characteristics of group I and 2 of PCa patients

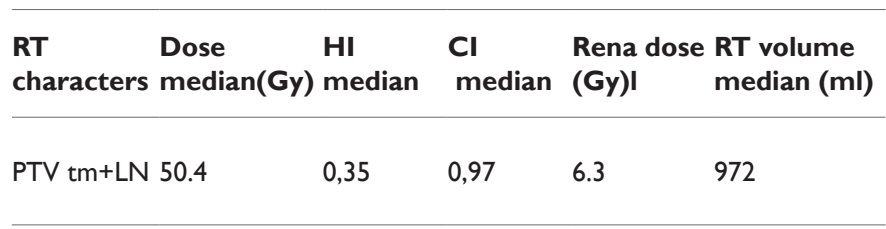

$\mathrm{HI}$, homogeneity index; $\mathrm{Cl}$, conformity index; TM, pancreatic tumor; LN, regional lymph nodes; PTV, planning target volume

Primary endpoint of this study was Overall survival (OS) rates. Secondary endpoint was treatment toxicities. OS time was defined as from begining of RT or CT since to death or the last follow-up date in survivors. Progression free survival time defined from begining of $\mathrm{RT}$ or CT to relapsing or times of metastases. Treatment response was assessed by Response Evaluation Criteria in Solid Tumors ver. 1.1. ${ }^{21}$ Treatment results determined to comparing dinamic abdomen CT/ MRI (Magnetic Resonance Imaging) or PET CT images and CA19-9 levels of patients which taken before and after treatments.

\section{Results}

Characteristics of patients were shown in Table $1 \& 2$. Complete response was achieved on 3 of 9 patients $(33.33 \%)$ and partial response on 3 of 9 patients (33.33\%). 2 of 9 patients $(22.22 \%)$ remained stable in $\mathrm{NS}+\mathrm{H}+\mathrm{CRT}$ group. Complete response obtained 2 of 11 patients $(18.18 \%)$ and partial on 4 of 11 patients $(36.36 \%)$ in CRT group according to RECIST ver. 1.1 (14.12) (Table 4).

Median survival was 15 months, threeyears survival $11.11 \%$ in $\mathrm{NS}+\mathrm{H}+\mathrm{CRT}$ group. The median survival was 10 months and threeyears survival $0 \%$ in the group of CRT. Recurrence sites and median recurrence months according to groups shown on Table 5. The patients whose pre-treatment levels of CA19-9>1000 U/mL demonstrated to 6 and 10months median survival time for CRT and $\mathrm{NS}+\mathrm{H}+\mathrm{CRT}$ groups respectively But the patients whose pre treatment levels of CA19-9 $<1000 \mathrm{U} / \mathrm{mL}$ has been to 14 and 20 monhts median survival time in CRT and $\mathrm{NS}+\mathrm{H}+\mathrm{CRT}$ groups respectively $(\mathrm{p}<0.05)$ (Figure 2). 
Table 4 Response rates for group I and 2 of PC a patient

\begin{tabular}{|c|c|c|c|}
\hline Groups and responses & Patient number & $\%$ & Median life (Month) \\
\hline $\mathrm{NS}+\mathrm{H}+\mathrm{CRT}$ & 9 & 100 & 15 \\
\hline CR & 3 & 33.33 & 20 \\
\hline PR & 3 & 33.33 & 18 \\
\hline S & 2 & 22.22 & 8 \\
\hline$P$ & I & II.II & 5 \\
\hline CRT & II & 100 & 10 \\
\hline CR & 2 & 18.18 & 15 \\
\hline PR & 4 & 36.36 & 12 \\
\hline S & 2 & 18.18 & 6 \\
\hline$P$ & 3 & 27.27 & 3 \\
\hline
\end{tabular}

NS, nigella sativa; H, pure honey; RCT, chemoradiotherapy; P, progression; $\mathrm{S}$, stationar; PR, partiel response; CR, complete response

Table 5 Recurrence sites and median recurrence times for group $I$ and 2 of PC a patients

\begin{tabular}{llll}
\hline CRT & Patient number & $\%$ & Median recurrence (Month) \\
\hline NS+H+CRT & 9 & 100 & 12 \\
Dist. met & 3 & 33.33 & 12 \\
CP & 2 & 22.22 & 13 \\
Local P & 5 & 55.55 & 14 \\
CRT & 11 & 100 & 8 \\
Dist. met & 9 & 81.81 & 8 \\
CP & 8 & 72.72 & 8 \\
Local P & 7 & 63.63 & 9
\end{tabular}

NS, nigella sativa; $H$, pure honey; $R C T$, chemoradiotherapy; $C P$, peritoneal carcinomatosis; P, progression; Dist.met, distance metastases; Met, metastases; $\mathrm{R}+\mathrm{CT}$, radiotherapy and chemotherapy

5 of 9 patients $(55.55 \%)$ of NS+H+CRT had local, 3 of 9 patients $(33.33 \%)$ had distant progression and 2 of $9(22.22 \%)$ had peritoneal carcinomatosis. 7 of 11 patients of CRT $(63.63 \%)$ had local, 9 of 11 patients $(81.81 \%)$ had distant progression and 8 of $11(72.72 \%)$ had peritoneal carcinomatosis after treatments.

7 of 9 patients experienced grade 2 haematologic (77.77\%), 1 of 9 patints $(11.11 \%)$ grade 3,6 of 9 patients grade 2 gastrointestinal toxicity $(66.66 \%)$ in NS+H+CRT. 11 of 11 patients experienced grade 1-2 haematologic (100\%), 3 of 11 patient grade 3 gastrointestinal and haematologic toxicity (33.33) in CRT according to RTOG/EORTC. ${ }^{22}$

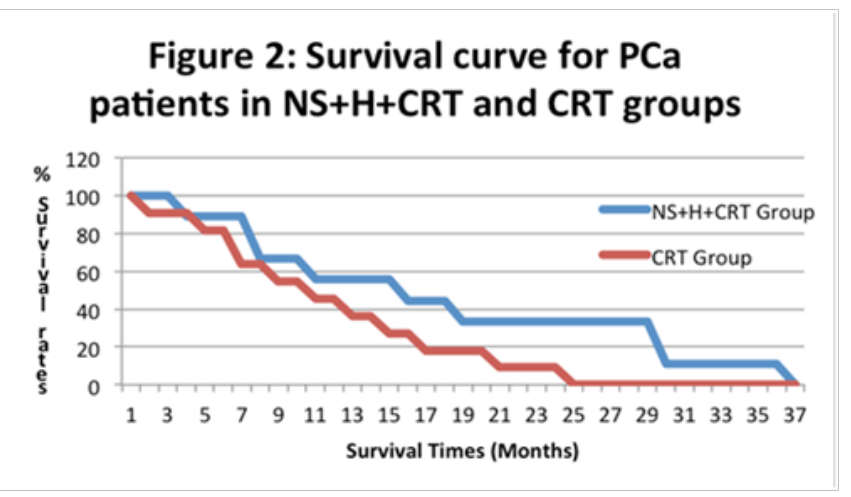

Figure 2 Survival curve for PC a patients in two groups.

\section{Discussions}

Median survival was 6 to 11.4 months in combined CT regimes with high toxicity rates, and 4.4 to 7.4 months in single CT regimes for advanced PCa. ${ }^{11,12,19,20,47}$ The median survival of advanced PCa increases to 10 months using concurrent CRT including gemcitabine or 5-FU with acceptable toxicity. ${ }^{13,14}$ Studies have shown anti-cancer and chemosensitivity effects of TQ, a predominant bioactive product of NS in PCa. ${ }^{46}$ Apoptotic activity could be increased by regulating antiapoptotic Bcl-2, Bcl-xL, XIAP, Caspase-3, Caspase-9, Bax molecules from pro-apoptotic molecules using pre-gemcitabine TQ in PCa. As well as the antiproliferative effect of TQanalogues and a successful chemosensitising agent with gemcitabine ${ }^{47}$ In the one in vitro trial, $60-80 \%$ anti-proliferative effect was observed with gemcitabine and oxaliplatin by giving TQbefore CT and only $15-25 \%$ effect was obtained with gemcitabine and oxaliplatin application. ${ }^{27}$

The achieved $66.66 \%$ complete and partial response and 15 months survival rates of NS+H+CRT group in this study were better than many other studies in literature although has been high pre-treatment levels of CA19-9 $>1000 \mathrm{U} / \mathrm{mL}$ than literature, also with acceptable toxicity. ${ }^{11-20}$ The median OS was 15 and 10 months in this study for $\mathrm{NS}+\mathrm{H}+\mathrm{RCT}$ and RCT groups respectively. Pre-treatment value of CA19-9 demonstrated one of the most prominent prognostic factors for PCa. Two large studies shown to the cut-off value of pre-treatment CA19-9 were evaluated $420 \mathrm{U} / \mathrm{mL}$ and $400 \mathrm{U} / \mathrm{mL}$ respectively as unfavourable predictor of OS in PCa patients who underwent CRT. ${ }^{48,49}$ Also, pre treatment levels of CA19-9 $>1000 \mathrm{U} / \mathrm{mL}$ indicated to dismal OS for PCa. ${ }^{50}$ In our study the patients whose pre-treatment levels of CA19-9>1000U/mL demonstrated to 6 and 10 monhts median survival time for CRT and $\mathrm{NS}+\mathrm{H}+\mathrm{CRT}$ groups respectively. But the patients whose pre treatment levels of CA19-9 $<1000 \mathrm{U} / \mathrm{mL}$ has been to 14 and 20months median survival time in CRT and NS+H+CRT groups respectively. Other studies shown to similar results that median OS being $12-14$ months in patients with $<1000 \mathrm{U} / \mathrm{mL}$, and 4-6months, in $\geq 1000 \mathrm{U} / \mathrm{mL}$ with used CRT in PCa patients. ${ }^{48-51}$

In this study demonstrated to low toxicity rates than other studies in literature. We observed $77.77 \%$ and $11.11 \%$ Grade $1-2$ and grade 3 haematologic toxicity respectively. The study also showed that grade 2 and grade 3 gastrointestinal toxicity $66.66 \%$ and $11.11 \%$ in NS+H+CRT. But grade 1-2 haematologic toxicity was experienced $100 \%$, grade 3 gastrointestinal and haematologic toxicity were $33.33 \%$ in CRT arm. Common Grade 3-4 gastrointestinal toxicities were achieved $20-43 \%$, infections were $13-30 \%, 60-75 \%$ grade $1-2,10-15 \%$ 3-4 haematologic toxicity in CRT arm on other studies. ${ }^{11-20,51,52}$ 
High dose RT applicated in some studies for increasing survival rates but severe acute and late toxicities occurred although improved OS..$^{53}$ The general advanced pancreatic cancer treatments were much toxic because pancreas with tumor and lymph node areas must be included in RT fields. ${ }^{54}$ Recent studies shown that RT of only gross tumour areas was sufficient for prevent marginal failures with low toxicity and increasing OS even high doses. ${ }^{46,55,56}$ It may be possible to identify more accurately to target delineations with increasing RT dose also improvements in both local control and OS rates using such as IMRT, SBRT, or proton therapy methods. Recently, SBRT can be applicated in only several days with achieving equivalent to or better tumor control rates than standard CRT regimes although without CT with limited toxicity especially elderly and low ECOG performance patients with pancreatic cancer. ${ }^{57} \mathrm{NS}$ and $\mathrm{H}$ can also improved to treatment outcomes with using low total dose of radiation with standard IMRT or SBRT methods with or without CT by reducing toxicities and increasing cytotoxic effects. ${ }^{58-62}$

\section{Conclusion}

In this study, $N S$ and $\mathrm{H}$ improved results with low toxicity in $\mathrm{NS}+\mathrm{H}+\mathrm{CRT}$ group.

\section{Recommendation}

The limitations in this study are a retrospective study and sample size is relatively small. But this study may be useful for literature because favorable OS and toxicity outcomes.

\section{Authorship}

Formulating the research questions: H.S.K., A.G.B. Designing the study: H.S.K., A.G.B., M.K.T. Carrying out: H.S.K., M.İ. Analyzing the data: H.S.K., AGB, MI, NO, ANA. Writing the article: H.S.K., AGB.

\section{Acknowledgments}

We thank to Güven Yücesan for the English review of this article.

\section{Conflict of interest}

There is no conflict of interest between this article and any other institution, company or persons.

\section{Funding}

There is no funding.

\section{References}

1. Epstein SS. Unlabeled milk from cows treated with biosynthetic growth hormones: a case of regulatory abdication. Int $J$ Health Serv. 1996;26(1):173-815.

2. Giaime E, Sunyach C, Herrant M, et al. Caspase-3-derived C-terminal product of synphilin-1 displays antiapoptotic function via modulation of the p53-dependent cell death pathway. J Biol Chem. 2006;281(17):11515-11522.

3. An alkaline diet and cancer. Canadian Cancer Society. 2012.

4. Balkwill F, Mantovani A. Inflammation and cancer: back to Virchow? Lancet. 2001;357(9255):539-545.

5. Kuska B. Calories and cancer: can we starve our way to health? $J$ Natl Cancer Inst. 2000;92(18):1466-1469.
6. Winick M. Calories and cancer. Hematol Oncol Clin North Am. 1991;5(1):1-6.

7. Calle EE, Rodriguez C, Walker-Thurmond K, et al. Overweight, obesity, and mortality from cancer in a prospectively studied cohort of U.S. adults. N Eng J Med. 2001;348(17):1623-1624.

8. Siegel RL, Miller KD, Jemal A. Cancer statistics. CA Cancer J Clin 2016;66(1):7-30.

9. Royal RE, Wolff RA, Crane CH. Cancer of pancreas. In: DeVita VT, Lawrence TS, Rosenberg SA, editors. cancer: principles \& practice of oncology. 9th ed. Philadelphia: Lippincott Williams \& Wilkins; 2011. p. $961-989$.

10. Krejs GJ (2010) Pancreatic Cancer: Epidemiology and Risk Factors. Dig Dis 28(2): $355-358$.

11. Park JK, Yoon YB, Kim YT, et al. Survival and prognostic factors of unresectable pancreatic cancer. J Clin Gastroenterol. 2008;42(1):86-91.

12. Cardenes HR, Chiorean EG, Dewitt J, et al. Locally advanced pancreatic cancer: current therapeutic approach. Oncologist. 2006;11(6):612-623.

13. Moertel CG, Frytak S, Hahn RG, et al. Therapy of locally unresectable pancreatic carcinoma: a randomized comparison of high dose (6000 rads) radiation alone, moderate dose radiation (4000 rads +5 -fluorouracil), and high dose radiation +5 -fluorouracil: The Gastrointestinal Tumor Study Group. Cancer. 1981;48(8):1705-1710.

14. A multi-institutional comparative trial of radiation therapy alone and in combination with 5-fluorouracil for locally unresectable pancreatic carcinoma. The Gastrointestinal Tumor Study Group. Ann Surg. 1979;189(2):205-208.

15. Kornek GV, Schratter-Sehn A, Marczell A, et al. Treatment of unresectable, locally advanced pancreatic adenocarcinoma with combined radiochemotherapy with 5-fluorouracil, leucovorin and cisplatin. Br J Cancer. 2000;82(1):98-103.

16. Hawes RH, Xiong Q, Waxman I, et al. A multispecialty approach to the diagnosis and management of pancreatic cancer. Am J Gastroenterol. 2000;95(1):17-31.

17. Burris $\mathrm{H}$, Moore $\mathrm{M}$, Andersen $\mathrm{J}$, et al. Improvements in survival and clinical benefit with gemcitabine as first-line therapy for patients with advanced pancreas cancer: a randomized trial. J Clin Oncol. 1997;15(6):2403-2413.

18. Louvet C, Labianca R, Hammel P, et al. Gemcitabine in combination with oxaliplatin compared with gemcitabine alone in locally advanced or metastatic pancreatic cancer: results of a GERCOR and GISCAD phase III trial. J Clin Oncol. 2005;23(15):3509-3516.

19. Berlin J, Catalano P, Thomas J, et al. Phase III study of gemcitabine in combination with fluorouracil versus gemcitabine alone in patients with advanced pancreatic carcinoma: Eastern Cooperative Oncology Group Trial E2297. J Clin Oncol. 2002;20(15):3270-3275.

20. Herrmann R, Bodoky G, Ruhstaller T, et al. Gemcitabine plus capecitabine compared with gemcitabine alone in advanced pancreatic cancer: a randomized, multicenter, phase III trial of the Swiss Group for Clinical Cancer Research and the Central European Cooperative Oncology Group. J Clin Oncol. 2007;25(16):2212-2217.

21. Eisenhauer EA, Therasse P, Bogaerts J, et al. New response evaluation criteria in solid tumours: revised RECIST guideline. Eur $J$ Cancer. 2008;45(2):228-247.

22. Cox JD, Stetz J, Pajak TF. Toxicity criteria of the Radiation Therapy Oncology Group (RTOG) and the European Organization for Research and Treatment of Cancer (EORTC). Int J Radiat Oncol Biol Phys. 1995;31(5):1341-1346. 
23. Türkdoğan MK, Ozbek $\mathrm{H}$, Yener $\mathrm{Z}$, et al. The role of Urtica dioica and Nigella sativa in the prevention of carbon tetrachloride-induced hepatotoxicity in rats. Phytother Res. 2003;17(8):942-946.

24. Singh S, Das SS, Singh G, et al. Composition. In Vitro Antioxidant and Antimicrobial Activities of Essential Oil and Oleoresins Obtained from Black Cumin Seeds (Nigella sativa L.) Biomed Res Int. 2014.

25. Shah S, Ray KS. Study on antioxidant and antimicrobial properties of black cumin (Nigella sativa Linn). Journal of Food Science and Technology. 2003;40(1):70-73.

26. Kiziltan HS. Cancer Prevention and Cancerogens (Kanserden Korunma ve Kanserojenler) Nobel Tip. 2017. 53,55.

27. Worthen DR, Ghosheh OA, Crooks PA. The in vitro anti-tumor activity of some crude and purified components of blackseed, Nigella sativa L. Anticancer Res. 1998;18(3A):1527-1532.

28. Banerjee S, Kaseb AO, Wang Z, et al. Antitumor activity of gemcitabine and oxaliplatin is augmented by thymoquinone in pancreatic cancer. Cancer Res. 2009;69(13):5575-5583.

29. Körber MI, Staribacher A, Ratzenböck I, et al. NFкB-Associated Pathways in Progression of Chemoresistance to 5-Fluorouracil in an In Vitro Model of Colonic Carcinoma. Anticancer Res. 2016;36(4):1631-1639.

30. Xu D, Ma Y, Zhao B, et al. Thymoquinone induces G2/M arrest inactivates $\mathrm{PI} 3 \mathrm{~K} / \mathrm{Akt}$ and nuclear factor- $\mathrm{B}$ pathways in human cholangiocarcinomas both in vitro and in vivo. Oncol Rep. 2014;31(5):2063-2070.

31. Hossen MS, Ali MY, Jahurul MHA, et al. Beneficial roles of honey polyphenols against some human degenerative diseases: A review. Pharmacol Rep. 2017;69(6):1194-1205.

32. Laura MP, Claire S, Mridula C. Honey and Cancer: Current Status and Future Directions. Diseases. 2016;4(4):30.

33. Alvarez-Suarez JM, Tulipani S, Díaz D, et al. Antioxidant and antimicrobial capacity of several monofloral Cuban honeys and their correlation with color, polyphenol content and other chemical compounds. Food Chem Toxicol. 2010;48(8-9):2490-2499.

34. Alvarez-Suarez JM, González-Paramás AM, Santos-Buelga C, et al Antioxidant characterization of native monofloral Cuban honeys. $J$ Agric Food Chem. 2010;58(17):9817-9824.

35. Jaganathan SK, Balaji A, Vellayappan MV, et al. A review on antiproliferative and apoptotic activities of natural honey. Anticancer Agents Med Chem. 2015;15(1):48-56.

36. Kassim M, Achoui M, Mustafa MR, et al. Ellagic acid, phenolic acids, and flavonoids in Malaysian honey extracts demonstrate in vitro antiinflammatory activity. Nutr Res. 2010;30(9):650-659.

37. Biswa M, Ahmad Z, Nik Min A. Topical application of honey in the management of radiation mucositis. A preliminary study. Support Care Cancer. 2003;11(4):242-248.

38. Wilson JM, Fokas E, Dutton SJ, et al. ARCII: A phase II trial of the HIV protease inhibitor Nelfinavir in combination with chemoradiation for locally advanced inoperable pancreatic cancer. Radiother Oncol. 2016;119(2):306-311.

39. Bogdanov S. Functional and biological properties of the bee products: a review. Bee Product Science. 2011.

40. Manyi-Loh CE, Ndip RN, Clarke AM. Volatile compounds in honey: a review on their involvement in aroma botanical origin determination and potential biomedical activities. Int J Mol Sci. 2011;12(12):9514-9532.

41. Raynaud A, Ghezali L, Gloaguen V, et al. Honey-induced macrophage stimulation: AP-1 and NF- $\mathrm{BB}$ activation and cytokine production are unrelated to LPS content of honey. Int Immunopharmacol. 2013;17(3):874-879.
42. Kassim M, Mansor M, Al-Abd N, et al. Gelam honey has a protective effect against lipopolysaccharide (LPS)-induced organ failure. Int J Mol Sci. 2012;13(5):6370-6381.

43. Nishio EK, Ribeiro JM, Oliveira AG, et al. Antibacterial synergic effect of honey from two stingless bees: Scaptotrigona bipunctata Lepeletier, 1836, and S. postica Latreille, 1807. Sci Rep. 2016;6.

44. Fataneh HD, Shahram A, Maryam TS, et al. Combination of Nigella sativa and Honey in Eradication of Gastric Helicobacter pylori Infection. Iran Red Crescent Med J. 2016;18(11):e23771.

45. Aghili KM, Makhzan-al-A. Tehran: Sabzara publications; 2011. p. $545-563$.

46. Reyshahry M. Hadith Encyclopedia of Medicine. Iran: Darolhadith publications; 2010. p. 431-433.

47. Kwak YK, Lee JH, Lee MA, et al. Definitive concurrent chemoradiotherapy in locally advanced pancreatic cancer. Radiat Oncol J. 2014;32(2):49-56.

48. Mu GG, Zhang LL, Li HY, et al. Thymoquinone Pretreatment Overcomes the Insensitivity and Potentiates the Antitumor Effect of Gemcitabine Through Abrogation of Notch1, PI3K/Akt/mTOR Regulated Signaling Pathways in Pancreatic Cancer. Dig Dis Sci. 2015;60(4):1067-1080.

49. Yusufi M, Banerjee S, Mohammad M, et al. Synthesis, characterization and anti-tumor activity of novel thymoquinone analogs against pancreatic cancer. Bioorg Med Chem Lett. 2013;23(10):3101-3114.

50. Micke O, Bruns F, Kurowski R, et al. Predictive value of carbohydrate antigen 19-9 in pancreatic cancer treated with radiochemotherapy. Int J Radiat Oncol Biol Phys. 2003;57(1):90-97.

51. Yoo T, Lee WJ, Woo SM, et al. Pretreatment carbohydrate antigen 19-9 level indicates tumor response, early distant metastasis, overall survival, and therapeutic selection in localized and unresectable pancreatic cancer. Int J Radiat Oncol Biol Phys. 2001;81(4):e623-e630.

52. Mehta J, Prabhu R, Eshpuniyani P, et al. Evaluating the efficacy of tumor markers CA 19-9 and CEA to predict operability and survival in pancreatic malignancies. Trop Gastroenterol. 2010;31(3):190-194.

53. Wang Z, Ren ZG, Ma NY, et al. Intensity modulated radiotherapy for locally advanced and metastatic pancreatic cancer: a mono-institutional retrospective analysis. Radiat Oncol. 2015;10:14.

54. Chung SY, Chang JS, Lee BM, et al. Dose escalation in locally advanced pancreatic cancer patients receiving chemo radiotherapy. Radiother Oncol. 2017;123(3):438-445.

55. Chang JS, Wang ML, Koom WS, et al. High-dose helical tomotherapy with concurrent full-dose chemotherapy for locally advanced pancreatic cancer. Int J Radiat Oncol Biol Phys. 2012;83(5):1448-1454.

56. Earle CC, Agboola O, Maroun J, et al. Cancer Care Ontario Practice Guidelines Initiative's Gastrointestinal Cancer Disease Site Group. The treatment of locally advanced pancreatic cancer: a practice guideline. Can J Gastroenterol. 2003;17:161-167.

57. Murphy JD, Adusumilli S, Griffith KA, et al. Full-dose gemcitabine and concurrent radiotherapy for unresectable pancreatic cancer. Int J Radiat Oncol Biol Phys. 2007;68(3):801-808.

58. Golden DW, Novak CJ, Minsky BD, et al. Radiation dose $\geq 54$ Gy and CA 19-9 response are associated with improved survival for unresectable, non-metastatic pancreatic cancer treated with chemoradiation. Radiat Oncol. 2012;7:156.

59. Rosati LM, Herman JM. Role of Stereotactic Body Radiotherapy in the Treatment of Elderly and Poor Performance Status Patients with Pancreatic Cancer. J Oncol Pract. 2017;13(3):157-166.

60. Tozzi A, Comito T, Alongi F, et al. SBRT in unresectable advanced pancreatic cancer: preliminary results of a mono-institutional experience. Radiat Oncol. 2013;8:148. 
61. Trakul N, Koong AC, Chang DT. Stereotactic body radiotherapy in the treatment of pancreatic cancer. Semin Radiat Oncol. 2014;24(2):140-147.
62. Terashima K, Demizu Y, Hashimoto N, et al. A phase I/II study of gemcitabine-concurrent proton radiotherapy for locally advanced pancreatic cancer without distant metastasis. Radiother Oncol. 2012;103:25-31. 